distracted from their social environment due to their illness, and their illnesses are considered as communicable diseases. It was seen that patients were tended to hide their diseases because of the fear of job loss and thinking they were being exposed to discrimination in the workplace.

Discussion After OD diagnosis, external stigmatisation is an important and prominent issue. Ensuring job security of the workers with OD and keeping them in working life (return to work and rehabilitation) should be prioritised to prevent stigmatisation. There is a need for investigations to explore the prevalence and causes of the stigmatisation in the workplaces due to chronic diseases including occupational diseases.

\section{BASIC TYPOLOGY OF SENTINEL AND ALERT APPROACHES TO IDENTIFY NEW AND EMERGING WORK-RELATED DISEASES}

\begin{abstract}
${ }^{1}$ Jelena Bakusic*, ${ }^{2}$ Annet Lenderink, 1,3 Sofie Vandenbroeck, ${ }^{1,3}$ Charlotte Lambreghts, ${ }^{4}$ Jos Verbeek, ${ }^{5}$ Stefania Curti, ${ }^{5}$ Stefano Mattioli, ${ }^{1,3}$ Lode Godderis. ${ }^{1}$ Environment and Health, KU Leuven, Belgium; ${ }^{2}$ Coronel Institute of Occupational Health, AMC/University of Amsterdam, The Netherlands; ${ }^{3}$ IDEWE, External Service for Prevention and Protection at Work, Heverlee, Belgium; ${ }^{4}$ Cochrane Work Review Group, Finnish Institute of Occupational Health, Kuopio, Finland; ${ }^{5}$ Department of Medical and Surgical Sciences, University of Bologna, Bologna, Italy
\end{abstract}

\subsection{6/oemed-2018-ICOHabstracts.372}

Objective Changes in working conditions give rise to new occupational health risks and work-related diseases (WRDs). Monitoring these new WRDs is essential for their early recognition and prevention and requires a comprehensive approach, using several complementary methods. The aim of this review is to provide an overview and basic typology of different approaches to detect new/emerging WRDs.

Methods We conducted an extensive scientific literature search combining terms for the following three concepts:

- surveillance/reporting systems;

- occupational/work-related diseases; and

- new or emerging risks.

In addition, a grey literature search was performed of both grey literature databases and relevant EU and research institute websites for additional resources.

Results We identified a total of 75 surveillance systems from 26 different countries. We set up a basic typology of these systems dividing them into four main groups. Compensationbased systems $(n=22)$ were designed to gather data for compensation purposes and are insurance-driven. Non-compensation-related systems $(n=34)$ were created with the aim of improving the collection and analysis of data to measure trends in occupational and work-related diseases. Sentinel systems $(n=12)$ were specifically designed to provide a warning signal that will initiate health interventions and preventive actions. Finally, public health surveillance systems $(n=7)$ aim to monitor the health of the general population, but can also be used for work-related surveillance. These four main types further differed in terms of disease coverage, means of data collection, evaluation of work-relatedness, follow-up of new/ emerging risks, link with prevention etc.

Conclusion Sentinel systems seem to have the most suitable approach to detect and alert to new/emerging WRDs. Nevertheless, systems identified in the other three groups can also contribute to identifying new/emerging WRDs, despite being primarily designed for other purposes.

\section{ESTIMATION OF THE GLOBAL BURDEN OF MESOTHELIOMA DEATHS FROM INCOMPLETE NATIONAL MORTALITY DATA}

${ }^{1}$ Odgerel Chimed-Ochir*, ${ }^{2}$ Ken Takahashi, ${ }^{3}$ Tom Sorahan, ${ }^{4}$ Tim Driscoll, ${ }^{5}$ Christina Fitzmaurice, ${ }^{1}$ Makoto Yoko-o, ${ }^{6}$ Kittisak Sawanyawisuth, ${ }^{7}$ Sugio Furuya, ${ }^{8}$ Fumihiro Tanaka, ${ }^{9}$ Seichi Horie, ${ }^{2}$ Nico van Zandwijk, ${ }^{10}$ Jukka Takala. ${ }^{1}$ Department of Environmental Epidemiology, Institute of Industrial Ecological Sciences, University of Occupational and Environmental Health, Kitakyushu, Japan; ${ }^{2}$ Asbestos Diseases Research Institute, Concord Clinical School, University of Sydney, Sydney, Australia; ${ }^{3}$ Institute of Applied Health Research, University of Birmingham, Birmingham, UK; ${ }^{4}$ School of Public Health, University of Sydney, Sydney, Australia; ${ }^{5}$ Department of Medicine, Division of Hematology, Institute for Health Metrics and Evaluation, Washington, USA; ${ }^{6}$ Department of Medicine, Faculty of Medicine, Khon Kaen University, Khon Kaen, Thailand; ${ }^{7} J a p a n$ Occupational Safety and Health Resource Center, Tokyo, Japan; ${ }^{8}$ Second Department of Surgery, University of Occupational and Environmental Health, Kitakyushu, Japan; ${ }^{9}$ Department of Health Policy and Management, Institute of Industrial Ecological Sciences, University of Occupational and Environmental Health, Kitakyushu, Japan; ${ }^{10}$ Workplace Safety and Health Institute, Ministry of Manpower, Singapore

\subsection{6/oemed-2018-ICOHabstracts.373}

Introduction Mesothelioma, one of the occupational cancer, is increasingly recognised as a global health issue and the assessment of its global burden is warranted.

Objectives To descriptively analyse national mortality data and to use reported and estimated data to calculate the global burden of mesothelioma deaths.

Methods For the study period of 1994 to 2014, we grouped 230 countries into 59 countries with quality mesothelioma mortality data suitable to be used for reference rates, 45 countries with poor quality data, and 126 countries with no data, based on the availability of data in the WHO Mortality Database. To estimate global deaths, we extrapolated the gender- and age-specific mortality rates of the countries with quality data to all other countries.

Results The global numbers and rates of mesothelioma deaths have increased over time. The 59 countries with quality data recorded 15011 mesothelioma deaths per year over the three most recent years with available data (equivalent to 9.9 deaths per million per year). From these reference data, we extrapolated the global mesothelioma deaths to be 38400 per year, based on extrapolations for asbestos use.

Conclusions Although the validity of our extrapolation method depends on the adequate identification of quality mesothelioma data and appropriate adjustment for other variables, our estimates can be updated, refined, and verified because they are based on commonly accessible data and are derived using a straightforward algorithm. Our estimates are within the range of previously reported values but higher than the most recently reported values.

\section{GENDER INEQUALITIES IN WORK ACCIDENTS AND OCCUPATIONAL MUSCULOSKELETAL DISORDERS: FINDINGS FROM THE 2013 BRAZILIAN NATIONAL HEALTH SURVEY}

Fernando Feijo, Clara Menegale, Fabrício Cardoso, Luís Henrique Santos, Matheus Lemos. Federal University Of Pelotas, Pelotas, Brazil

\subsection{6/oemed-2018-ICOHabstracts.374}

Introduction Considering the need to deepen the understanding of inequities in occupational health, this study aimed to describe the prevalence of work accidents and occupational musculoskeletal disorders (MSD) in the Brazilian population, analysing gender inequalities. 
Methods Cross-sectional study with secondary data from the 2013 Brazilian National Health Survey, with a representative sample of the Brazilian population, including 60202 individuals. Descriptive statistics were used to present the social and demographic variables and the occurrence of the outcome. Chi-square was performed to test differences between groups. Results A prevalence of MSD was 2.2 times higher in females compared to males (prevalence of $3.3 \%$ and $1.5 \%$, respectively). The prevalence of occupational accidents was $47 \%$ lower among women compared to men (prevalence of $1.4 \%$ and $3.1 \%$, respectively).

Discussion Although MSD and work accidents have a seemingly low prevalence in relative values, absolute numbers of cases are worrying, showing a non-favourable picture for working population health. Theses inequalities on health outcomes occurrences can be partially explained by the unequal way that men and women are inserted in Brazilian working market

\section{CAUSE-SPECIFIC SICKNESS ABSENCE BY OCCUPATION}

${ }^{1}$ Therese N Hanvold*, ${ }^{1}$ Karina Corbett, ${ }^{1,2}$ Petter Kristensen, ${ }^{1}$ Ingrid S Mehlum. ${ }^{1}$ National Institute of Occupational Health, Oslo, Norway; ${ }^{2}$ Institute of Health and Society, University of Oslo, Norway

\subsection{6/oemed-2018-ICOHabstracts.375}

Introduction To identify workers facing particular challenges related to occupational exposure and health is valuable, as work environment plays an important role in terms of sickness absence (SA) and return to work. Assessing vulnerable occupational groups related to SA may facilitate decision makers in terms of allocating resources and interventions. The aim of this paper was to assess cause-specific SA rates by occupation and evaluate occupational specific excess fractions for SA. Methods The source population was a Norwegian birth cohort (all 626928 live-born individuals born between 1967 and 1976). Individual records on physician-diagnosed SA spells lasting $>16$ calendar days were obtained from the Norwegian event database FD-Trygd. The incidence rate of SA was estimated annually during 2005-2009. SA with musculoskeletal and mental diagnoses, was estimated for 31 occupational groups classified by ISCO-88 on a 2-digit level. Excess causespecific SA was also estimated for each of the 31 occupations. All analyses were stratified by gender.

Result Workers in sales and service occupations and metal and machinery workers had the highest annual rates of musculoskeletal SA. Male metal and machinery workers had a 91\% increased rate, compared to male corporate managers, while female workers in sales and services occupations had an $83 \%$ increased rate, compared to female corporate managers. For SA related to mental disorders, personal care workers had the highest rates among both men and women.

Discussion Occupation is an imprecise measure of work exposure and in the continued work on these data we will use a newly developed job exposure matrix to estimate the associations between specific physical and psychosocial exposures and cause-specific sickness absence by occupation.

\section{MINI BREAK INTERVENTION IN PREVENTING ASTHENOPIA AMONG DRAWING WORKERS USING STANDARD AND WIDESCREEN SIZE VDT AT CONSTRUCTION COMPANY IN JAKARTA}

B Hidayat*, T Rahayu, A Kekalih. Univercity of Indonesia, Indonesia

\subsection{6/oemed-2018-ICOHabstracts.376}

Introduction Astenopia has the effect of decreasing work productivity and health condition. Although the computer has not been proven to make permanent damage to the eyes but temporary discomfort due to tired eyes can reduce productivity. The impact is on lost working hours and reduced job satisfaction. In indonesia, In a diagnostic test of tired eye screening tool for office workers in north Jakarta, astenopia prevalence was found at $80 \%$. Asthenopia among drawing workers is becoming my attention because there are significant number of drawing workers as office workers in Jakarta, Indonesia and limited data regarding their health effect from their work Methods This is an experimental study with cross over design. The number of subjects who participated in this study were 66 participants. Intervention of no mini break and mini break were given to workers who used VDT size 4:3 and VDT size 16:9. Data was revealed from the difference of NPC before and after 4 hours of VDT exposure and 4 hours of exposure with a 15 min mini break after 2 hours of work to both groups (sub group of VDT 4:3 and VDT 16:9) using RAF (Royal Air Force) ruler.

Results The users of VDT size 4:3 have difference of NPC $2,89 \pm 1,11 \mathrm{~cm}$ in no mini break intervention and 1,42 $\pm 1,01 \mathrm{~cm}$ in mini break intervention. The users of VDT size 16:9 have difference NPC $3,02 \pm 1,04 \mathrm{~cm}$ in no mini break intervention and $1,41 \pm 1,10 \mathrm{~cm}$ in mini break intervention. The difference of convergence power between no mini break and mini break intervention for VDT size $4: 3 \quad(p=0.000)$ and size 16:9 users $(p=0.000)$ was statistically significant. There was no significant difference statistically in convergence power in no mini break intervention between VDT size 4:3 and size 16:19 users $(p=0,6251)$ and neither in mini break intervention between VDT size 4:3 and size 16:9 users $(p=0,9694)$.

Conclusion The convergence power is different significantly between working without mini break and with mini break in both of VDT users size 4:3 and 16:9. There is no diference significantly between VDT users size $4: 3$ and 16:9 in no mini break intervention as well as mini break intervention. This is probably because the measurement is only based on NPC and experimental limitations. It takes other parameters to measure asthenopia due to VDT usage as asthenopia is a sign of computer vision syndrome.

\section{TOTAL BURDEN OF PRESENTEEISM, ABSENTEEISM AND MEDICAL/PHARMACEUTICAL COST BY HEALTH RISKS}

Koki Kimura*, Tomohisa Nagata, Makoto Ohtani, Koji Mori, Masako Nagata, Shigeyuki Kajiki, Yoshihisa Fujino, Shinya Matsuda. University of Occupational and Environmental Health, Japan, Kitakyushu, Japan

10.1136/oemed-2018-ICOHabstracts.377 